\title{
A comprehensive review of vaccination in patients with inflammatory bowel diseases: An Indian perspective
}

\author{
Bhavik Bharat Shah ${ }^{1} \cdot$ Mahesh Kumar Goenka ${ }^{1}$
}

Received: 15 April 2020 / Accepted: 22 June 2020 / Published online: 26 August 2020

(C) Indian Society of Gastroenterology 2020

\begin{abstract}
The disease burden of inflammatory bowel diseases (IBD) in India is estimated to be one of the highest in the world in the near future. Patients with IBD, particularly those on immunosuppressive therapy, are at increased risk for developing vaccinepreventable illnesses. Adult vaccination policy and vaccination in patients with IBD are presently being at a very low level in India. This review discusses in detail the need for vaccination, levels of immunosuppression, a brief account of live and inactivated vaccines, available vaccines, and their utility in patients with IBD, with a special focus on recent recommendations.
\end{abstract}

Keywords Biologicals · Biosimilars · Crohn disease · Immunosuppression · Infection prevention · Ulcerative colitis · Vaccine recommendations $\cdot$ Vaccine types

\section{Introduction}

Inflammatory bowel diseases (IBD), including ulcerative colitis (UC) and Crohn's disease (CD), comprise a group of chronic immune-mediated disorders of the gastrointestinal system. The prevalence of IBD is increasing worldwide [1]. With the ongoing population explosion in India, the disease burden of IBD in India is estimated to be one of the highest in the world in the near future [2]. The use of steroids and long-term immunosuppression with tumor necrosis factor (TNF)-alpha antagonist agents and immunomodulators, forms the basis of treatment in IBD. These immunosuppressants increase the risk of infections and their severity as well as infection-related mortality in patients with IBD [3]. The widespread use of such therapies warrants preventive measures, which include optimal immunization. The role of appropriate vaccination is highlighted in these patients as one of the top ten quality process indicators [4]. In this review, we attempt to improve gastroenterologist's knowledge and emphasize the importance of vaccination in IBD patients.

Mahesh Kumar Goenka

mkgkolkata@gmail.com

1 Institute of Gastrosciences and Liver, Apollo Gleneagles Hospitals, 58 Canal Circular Road, Kolkata 700 054, India

\section{Need for vaccination in patients with IBD}

Patients with IBD have a life expectancy similar to the general population, except for patients with long-standing severe Crohn's disease [5]. Infections are, however, common causes of death in patients with IBD. A study published by Kirchgesner et al. in 2018 showed that, among 190,694 patients with IBD, serious infections occurred in 8561 and 674 had opportunistic infections. The investigators also reported that combination therapy was accompanied by higher risks of serious and opportunistic infections than anti-TNF monotherapy [6]. A similar finding was noted by a recent meta-analysis, which concluded that the combination of TNF antagonists, with systemic steroids, is associated with a higher risk of serious infection. Furthermore, monotherapy with an immunomodulator (azathioprine, methotrexate) is associated with a lower risk of infection as compared with monotherapy with a TNF antagonist [7]. The risk of HBV reactivation is also higher in patients with IBD on chronic immunosuppression [8].

The increased rate of infection in the IBD cohort is attributable not only to immunosuppression but also to the disease process, defective innate immune mechanisms, and other associated co-morbid conditions [9]. Data show that IBD patients are specifically at higher risk for vaccine-preventable diseases, as vaccination rates are low in these patients [10]. As the rate of infections is high in IBD patients, there is an obvious need to vaccinate these cohorts of patients. 


\section{Prevailing vaccination practice in IBD patients}

Data from the West suggest that IBD patients do not receive preventive care at the same rate as patients in a general medical practice [11]. A survey by Melmed et al. showed that, among 146 IBD patients, nearly $90 \%$ had factors that placed them at high risk for infection, including immune suppression. Only $28 \%$ of these patients received influenza vaccines, and less than $10 \%$ had been immunized against pneumococcus [10]. Lack of awareness, insufficient counseling by the health care providers, doubt about the indication, and fear of side effects have been the most common reasons for nonimmunization in patients with IBD [12].

Expert consensus guidelines suggest that the complete history of immunization should be reviewed before starting patients on immunosuppressive therapy [13]. The importance of vaccinating patients early in the course of the disease should be recognized. However, gastroenterologists do not often take an immunization history or discuss the needs of immunizations with their patients. The data also suggest that they have inadequate knowledge about recommended vaccinations for IBD patients. Additionally, almost one-third of them reported that they would incorrectly recommend a live vaccine to an IBD patient on a biologic therapy [14]. Exacerbations of CD or UC are not thought to be caused by vaccinations. Data for specific vaccines are lacking, but the absence of a clear putative mechanism and reports of an association suggests this to be an unlikely consequence of any vaccine [13]. Overall, there needs to be a paradigm shift in terms of vaccination of IBD patients, who are likely to get infected in response to their IBD treatments.

\section{Levels of immunosuppression}

Evaluating the patient's immunosuppression level is extremely important before initiating the vaccination program in patients with IBD. Table 1 gives a precise definition of levels of immunosuppression $[15,16]$.

\section{Vaccines}

Scientific research has led to the development of numerous types of vaccines that safely elicit immune responses that protect against a particular infection. Researchers continue to investigate novel vaccine strategies for the prevention of existing and emerging infectious diseases. There are two major subtypes of vaccines: live vaccines and inactivated vaccines. Table 2 explains, in brief, the difference between these two vaccine subtypes and enlists adult vaccines indicated in IBD, which are available in India.

\section{Vaccination recommendations}

Ideally, the vaccination program in the patients with IBD should be initiated at the diagnosis of the disease and/or before immunosuppressant therapy. All the adult IBD patients, whether on immunosuppressive treatments or not, should receive non-live vaccines $[13,17]$. Live vaccines are particularly contraindicated in patients on high-dose immunosuppressants given the risk of disseminated infection. Ideally, patients should be vaccinated when their disease is in a quiescent state and before starting immunosuppressive therapy. Live vaccines should be administered $\geq$ 4 weeks prior to immunosuppression and should be avoided within 1-3 months of stopping high-level immunosuppression. Below we describe each of the vaccines used in these patients with their dosing schedule (Tables 3 and 4) [13, 15, 17, 18].

\section{Inactivated vaccines}

\section{Influenza vaccine}

Influenza is usually a respiratory illness with symptoms of fever, myalgia, headache, cough, and sore throat. Influenza infection occurs as an annual epidemic. Due to the frequent antigenic drift that occurs in this virus, a new vaccine is produced annually. In India, the rise in influenza infection rates in the inter-seasonal period of the year, as evident in the year 2012 and 2015, is also being increasingly noted [19]. Influenza vaccines can be in an inactivated form that is injected intramuscularly, and a live form which is administered intranasally. A live vaccine is to be avoided in immunosuppressed patients. In a recently conducted study of 140,480 patients with IBD as compared with patients without IBD, the former had a higher risk of influenza infection and the need for hospitalization. This risk is higher when patients are treated with immunosuppressive therapies. Furthermore, patients with IBD and influenza infection are more likely to acquire pneumonia and the need for hospitalization [20].

Three different strains of influenza virus exist, namely A, B, and C. Strain C causes mild symptoms and do not cause epidemics. Vaccines are produced against the influenza strain A and B. Inactivated vaccine is found to be safe and well-tolerated in patients with IBD. Rates of seroprotection against strain A, regardless of immunosuppression status, are similar to the general population. However, seroprotection in immunosuppressed patients is attenuated towards the strain B of the vaccine [21]. It is observed that the influenza vaccination significantly lowers the risk of influenza in immunosuppressed vaccinated patients compared with those who are not vaccinated [22]. It is also studied that repeated yearly vaccination contributes to a consistent seropositive state [23]. There are studies which have analyzed the high-dose influenza vaccines, which contain four times more hemagglutinin than the standard dose vaccine. A study showed that patients with 
Table 1 Levels of immunosuppression

High-level immunosuppression

- Treatment $\geq 20 \mathrm{mg} /$ day of prednisone or equivalent for $\geq 2$ weeks and within 3 months of stopping

-Treatment with 6-mercaptopurine $\geq 1.5 \mathrm{mg} / \mathrm{kg} /$ day

Azathioprine $\geq 3 \mathrm{mg} / \mathrm{kg} /$ day

Methotrexate $\geq 0.4 \mathrm{mg} / \mathrm{kg} /$ week or discontinuation within 3 months

-Treatment with rituximab, infliximab, golimumab adalimumab, certolizumab pegol, natalizumab, or vedolizumab, or discontinued within 3 months

-Patients with HIV infection with a CD4 T-lymphocyte count $<200$ cells $/ \mathrm{mm}^{3}$

-Patients with combined primary immunodeficiency disorder (e.g. severe combined immunodeficiency)

-Patients receiving cancer chemotherapy, within 2 months after solid organ transplantation
Low-level immunosuppression

-Treatment $<20 \mathrm{mg} /$ day of prednisone or equivalent for $\geq 2$ weeks

-Treatment with 6-mercaptopurine $<1.5 \mathrm{mg} / \mathrm{kg} /$ day

Azathioprine $<3.0 \mathrm{mg} / \mathrm{kg} /$ day

Methotrexate $<0.4 \mathrm{mg} / \mathrm{kg} /$ week or discontinuation within 3 months

-Patients with significant protein-calorie malnutrition

-Asymptomatic HIV-infected patients with CD4 T-lymphocyte counts of $200-499$ cells $/ \mathrm{mm}^{3}$

$H I V$ human immunodeficiency virus

IBD treated with anti-TNF monotherapy receiving high-dose influenza vaccine had significantly higher seroprotection than standard dose vaccines [24]. The inactive influenza vaccine is safe in patients with IBD on immunosuppressants, with minimal-vaccine associated local reactions without any increase in IBD flares [25]. Hence, the IBD patients should receive the inactivated or recombinant influenza vaccination (available in trivalent or quadrivalent forms) annually to target the evolving viral strain, regardless of the immunosuppression use.

\section{Pneumococcal vaccine}

Streptococcus pneumoniae is a common cause of pneumonia, meningitis, and septicemia, with a high fatality rate in India
[26]. Patients with IBD on immunosuppression, particularly corticosteroids and anti-TNF drugs, are at an increased risk of acquiring pneumococcal infections [27, 28]. Hospitalized IBD patients with pneumonia are at increased risk of death during hospitalization [29]. Two forms of pneumococcal vaccines are recommended, namely the 13 -valent conjugate vaccine (PCV13) and the 23-valent polysaccharide vaccine (PPSV23). Both these vaccines are recommended as these provide a broader seroprotection against multiple pneumococcal strains. The current recommendation advocates that the patients with IBD on immunosuppressive medications should be vaccinated once with the pneumococcal conjugate vaccine (PCV13) followed by pneumococcal polysaccharide vaccine (PPSV23) at least 8 weeks later. They should then receive a

Table 2 Difference between live and inactivated vaccines

\begin{tabular}{|c|c|}
\hline Live vaccine & Inactivated vaccine \\
\hline $\begin{array}{l}\text {-Vaccines in which an attenuated form of an } \\
\text { infectious organism replicates to produce } \\
\text { an immune response }\end{array}$ & $\begin{array}{l}\text {-Vaccines consisting of viral or bacterial proteins and } \\
\text { carbohydrates that are grown in culture and denatured } \\
\text { using heat or chemical methods }\end{array}$ \\
\hline $\begin{array}{l}\text {-Live vaccines typically produce a more robust } \\
\text { immune response compared with inactivated vaccines }\end{array}$ & $\begin{array}{l}\text { - Because the organism of interest is inactivated, these } \\
\text { vaccines typically produce a weaker immune response }\end{array}$ \\
\hline - Can pose a risk to immunosuppressed recipients & -Inactivated vaccines can be safely administered to patients \\
\hline -Live vaccines recommended in IBD patients & on immunosuppressive therapy \\
\hline Influenza nasal & -Inactivated vaccines recommended in IBD patient \\
\hline Varicella Zoster (Zostavax) & Influenza injection \\
\hline \multirow[t]{9}{*}{ Measles, mumps, and rubella (MMR) } & Tetanus/diphtheria/pertussis (Tdap) \\
\hline & Pneumococcal 13 valent (PCV13) \\
\hline & Pneumococcal polysaccharide (PPSV23) \\
\hline & Hepatitis A \\
\hline & Hepatitis B \\
\hline & Haemophilus influenza type B (Hib) \\
\hline & Human Papilloma virus \\
\hline & Meningococcal quadrivalent vaccine \\
\hline & Varicella Zoster (Shingrix) \\
\hline
\end{tabular}


Table 3 Inactivated vaccine schedule for inflammatory bowel disease patients

\begin{tabular}{|c|c|c|c|}
\hline $\begin{array}{l}\text { Vaccine (brand } \\
\text { names) }\end{array}$ & Target group & Dosing schedule ${ }^{a}$ & Comments \\
\hline $\begin{array}{l}\text { Influenza } \\
\quad \text { (FluQuadri) }\end{array}$ & All patients & $0.5 \mathrm{~mL}$ IM annually & $\begin{array}{l}\text { Live-attenuated intranasal influenza vaccine is } \\
\text { contraindicated in immunosuppressed patients }\end{array}$ \\
\hline $\begin{array}{l}\text { Hepatitis A (Havarix, } \\
\text { Biovac A) }\end{array}$ & All patients & $0.5 \mathrm{~mL} \mathrm{IM}$ at 0 and 6 months & Titer testing before vaccination is recommended \\
\hline $\begin{array}{l}\text { Hepatitis B } \\
\text { (Engerix-B, } \\
\text { Cefvac-B, } \\
\text { GeneVac-B, } \\
\text { Shanvac-B) }\end{array}$ & All patients & $1 \mathrm{~mL} \mathrm{IM}$ at 0,1 and 6 months & $\begin{array}{l}\text { Antibody titer testing before vaccination is } \\
\text { recommended. Double-dose vaccine, accelerated } \\
\text { double-dose, or combined hepatitis A and B vac- } \\
\text { cine is also recommended }\end{array}$ \\
\hline $\begin{array}{l}\text { Human papilloma } \\
\text { virus (Gardasil) }\end{array}$ & $\begin{array}{l}9-14 \text { years } \\
15-26 \text { years } \\
27-45 \text { years }\end{array}$ & $\begin{array}{l}0.5 \mathrm{~mL} \mathrm{IM} \text { at } 0 \text { and } 6 \text { months } \\
0.5 \mathrm{~mL} \mathrm{IM} \text { at } 0,2 \text {, and } 6 \text { months } \\
0.5 \mathrm{~mL} \mathrm{IM} \text { at } 0,2 \text {, and } 6 \text { months }\end{array}$ & $\begin{array}{l}\text { Quadrivalent vaccine targeted against HPV types } 6 \text {, } \\
11,16 \text {, and } 18 \text { is recommended } \\
\text { Based on shared clinical decision between patient and } \\
\text { care provider }\end{array}$ \\
\hline $\begin{array}{l}\text { Tetanus diphtheria } \\
\text { Pertussis-Tdap } \\
\text { (Boostrix) }\end{array}$ & All patients & $0.5 \mathrm{~mL}$ IM single dose between age $11-64$ years & $\begin{array}{l}\text { A tetanus diphtheria- } \mathrm{Td} \text { vaccine booster every } 10 \\
\text { years is recommended }\end{array}$ \\
\hline $\begin{array}{l}\text { Pneumococcus } \\
\quad \text { (Prevenar 13, } \\
\text { Pneumovax 23) }\end{array}$ & All patients & $\begin{array}{l}0.5 \mathrm{~mL} \text { IM PCV13 followed by a dose of } 0.5 \mathrm{~mL} \text { IM } \\
\text { PPSV23 after } 2-12 \text { months; another dose of } \\
\text { PPSV23 should be administered } 5 \text { years after the } \\
\text { initial PPSV } 23 \text { dose and the third dose after age of } \\
65 \text { years }\end{array}$ & $\begin{array}{l}\text { Patients may receive PCV13 } 1 \text { year following } \\
\text { PPSV23 if the later vaccine was given first }\end{array}$ \\
\hline $\begin{array}{l}\text { Meningococcal } \\
\text { Vaccine } \\
\text { (Menactra) }\end{array}$ & $\begin{array}{l}\text { High-risk }^{\mathrm{b}} \\
\text { patients } \\
\text { between age } \\
2-55 \text { years }\end{array}$ & $0.5 \mathrm{~mL}$ IM two doses over $8-12$ weeks apart & $\begin{array}{l}\text { Due to interference with PCV } 13 \text { immune response, } \\
\text { Menactra should be given at least after 1-month } \\
\text { interval of PCV13 vaccine }\end{array}$ \\
\hline $\begin{array}{l}\text { Herpes Zoster } \\
\text { (Shingrix) }\end{array}$ & $\begin{array}{l}\text { Patient age }> \\
50 \text { years }\end{array}$ & $0.5 \mathrm{~mL}$ IM two doses at 0 and $2-6$ months & $\begin{array}{l}\text { Patients who previously received the live vaccine } \\
\text { should complete the Shingrix series as } \\
\text { recommended }\end{array}$ \\
\hline
\end{tabular}

$I M$ intramuscular, $H P V$ human papillomavirus, $T d$ Tetanus and diphtheria vaccine, $P C V$ pneumococcal vaccines, $P P S V$ pneumococcal polysaccharide vaccine, $T$ dap tetanus, diphtheria, and acellular pertussis

${ }^{a}$ Dose of vaccine may vary. Please refer to the product monograph before administration

${ }^{\mathrm{b}}$ See text

second dose of PPSV23 5 years after the first dose and finally a third dose after the age of 65 year. Alternatively, patients may receive PCV13 1 year following PPSV23 if the later vaccine was given first [13].

A multi-center study conducted in India showed that a single dose of PCV13 vaccine is safe and immunogenic for preventing pneumococcal pneumonia in adults aged 50 to 65 year [30]. This vaccine is generally safe and well-tolerated with minimal local reactions and without risk of IBD flare. Available data for pneumococcal vaccination in IBD patients suggest that combination therapy with an immunomodulator and a biologic agent may blunt vaccine responses significantly. Therefore, while all immunosuppressed adults can safely receive the vaccine, it should ideally be administered before initiation of immunosuppression [31, 32].

\section{Hepatitis A and B viruses}

Hepatitis A virus is the common cause of viral hepatitis worldwide and in India [33]. Hepatitis A titer should be checked in all patients with IBD. If patients are not seroprotected, a 2-dose schedule of the hepatitis A vaccine should be administered at 0 and 6 months. The overall efficacy of the hepatitis A vaccine in IBD patients is higher than $90 \%$. Seroconversion rates are slightly diminished in patients on anti-TNF and/or other immunosuppressive therapy; however, they persist in being higher than $90 \%$ without any significant adverse reactions [34].

The prevalence of hepatitis B virus (HBV) infection in IBD patients is higher compared to healthy controls [35]. The risk of hepatitis B flare following the immunosuppressive therapy is also high [36]. Furthermore, reactivation of HBV infection and subsequent acute liver failure requiring urgent liver transplantation or lethal outcome can occur during anti-TNF therapy [37]. Therefore, HBV infection and vaccination status should be evaluated before starting anti-TNF therapy by determining the presence of HBV surface antigen, total core antibody, and surface antibody. HBV core antibody is measured to exclude a latent HBsAg negative HBV infection. In those patients with an isolated HBc antibody, an HBV DNA level should be measured. If the HBV DNA is negative, a 
Table 4 Live vaccine schedule for inflammatory bowel disease patients ${ }^{\mathrm{a}, \mathrm{b}}$

\begin{tabular}{|c|c|c|c|}
\hline Vaccine (brand names) & Target group & Dosing schedule ${ }^{\mathrm{b}}$ & Comments \\
\hline $\begin{array}{l}\text { Mumps, measles, rubella } \\
\text { (M-M-R) }\end{array}$ & If vaccination history unknown & $\begin{array}{l}\text { Two doses } 0.5 \mathrm{~mL} \mathrm{IM} \text { at least } 4 \\
\text { weeks apart }\end{array}$ & $\begin{array}{l}\text { Contraindicated in patients on } \\
\text { immunosuppression }\end{array}$ \\
\hline Varicella (Zuvicella) & If vaccination history unknown & $\begin{array}{l}\text { Two doses } 0.5 \mathrm{~mL} \mathrm{SC} \text { at least } 4 \\
\text { weeks apart }\end{array}$ & $\begin{array}{l}\text { Contraindicated in patients on } \\
\text { immunosuppression }\end{array}$ \\
\hline Herpes zoster (Zostavax) & $\begin{array}{l}\text { Patients age }>50 \text { years with unknown } \\
\text { vaccination history irrespective of } \\
\text { previous exposure }\end{array}$ & Single dose of $0.65 \mathrm{~mL} \mathrm{SC}$ & $\begin{array}{l}\text { Patients on low-level } \\
\text { immunosuppression may } \\
\text { be vaccinated }\end{array}$ \\
\hline
\end{tabular}

$I M$ intramuscular, $S C$ subcutaneous

${ }^{\text {a }}$ Live vaccines should be administered in IBD patients 4-6 weeks before initiating immunosuppressive therapy

${ }^{\mathrm{b}}$ Dose of vaccine may vary. Please refer to the product monograph before administration

complete HBV vaccination schedule as recommended should be administered.

The response rate to HBV vaccination is significantly lower in IBD patients than the general population. However, immunosuppressive therapy for IBD does not influence the vaccine response [38]. The response rate can be improved by administering double-dose vaccination or 3 additional vaccine doses at 0,1 , and 6 months after titer assessment [39]. Titer should be checked 1 to 2 months after the last dose, to confirm seroprotection $[15,17]$. Titer less than $10 \mathrm{mIU} / \mathrm{mL}$ is considered inadequate. In these circumstances, a booster dose is recommended, and after that, if titers persist to be low, a readministration of HBV vaccination series is suggested. However, even after administering a booster vaccination, the rate of seroprotection is significantly lower than the general population. The combined use of HAV and HBV vaccines also seems to improve the overall seroconversion rates [15]. Indian consensus suggests the administration of accelerated double doses ( $40 \mu \mathrm{g}$ at 0,1 , and 2 months) of the HBV vaccine in immunosuppressed patients, followed by the two yearly titer evaluation to confirm immunity [40].

The Food and Drug Administration approved a new twodose HBV vaccine (HepB-CpG, Heplisav-B, Dynavax) in July 2017, which can be given over 1 month instead of 6 months. The HepB-CpG vaccine is a yeast-derived vaccine prepared with a novel immunostimulatory sequence adjuvant, recommended for use in all patients over the age of 18 year. However, no study has evaluated this new vaccine in IBD populations and the Indian consensus on HBV vaccination was released before the advent of this new vaccine [41].

\section{Human papilloma virus}

A strong causal association between the human papillomavirus (HPV) and cervical, penile, anal, and oropharyngeal cancers has been demonstrated [42]. As per the worldwide cancer database 2018, 60,000 deaths and 97,000 new cases were detected in India alone [43]. Cervical cancer is the second most common cancer in Indian women aged 15-44 years. The high burden of cervical cancer in India and Southeast Asian countries is due to poor to moderate living standards, a high prevalence of HPV infection, lack of screening, and poor overall HPV vaccination [44]. The incidence of HPVrelated cancer is typically higher in IBD patients with an overall poor prognosis and increased cancer-related mortality as compared to non-IBD patients [45]. A recently published meta-analysis found that the patients with IBD on immunosuppressant therapy had an increased risk of cervical highgrade dysplasia/cancer as compared to healthy controls [46].

Two types of HPV vaccines are commonly used. A bivalent vaccine (Cervarix) that is effective against 2 HPV serotypes $(16,18)$, and a quadrivalent vaccine (Gardasil) effective against 4 HPV serotypes $(6,11,16$, and 18) associated with the highest risk of progression to cervical and anogenital cancer. A quadrivalent vaccine is recommended for all women and men with IBD up to the age of 26 year. Gardasil is given in three doses at 0,2 , and 6 months for patients aged 15 26 year $[13,15]$. As per the recent recommendation, children aged 9-14 year may instead receive only two doses 6 months apart. On October 5, 2018, the Food and Drug Administration (FDA), USA approved Gardasil for adults aged 27 through 45 years [47], while its use in a specific IBD population is unclear at this point. This vaccine is found to be equally efficacious in patients with IBD on immunosuppressants, and there are no clinically significant vaccine-associated adverse events [48]. It is also recommended for all the women with IBD on immunosuppressive therapy to undergo annual cervical cancer screening [13].

\section{Tetanus, diphtheria, and pertussis}

Tetanus is a rare neuromuscular condition caused by the neurotoxin produced by Clostridium tetani. Bordetella pertussis causes a highly contagious upper respiratory infection known as whooping cough. Diphtheria is a serious bacterial infection caused by Corynebacterium diphtheriae, usually affecting the 
mucous membranes of the nose and pharynx. Tetanus and diphtheria vaccine $(\mathrm{Td})$ is recommended every 10 years, and the tetanus, diphtheria, and pertussis (Tdap) vaccine should be given at least once during this period. IBD patients on immunosuppressants have lower antibody concentrations to tetanus toxoid, diphtheria, and pertussis [49-51]. Because of low antibody titers in patients receiving immunosuppressants, it is ideal to receive Tdap before starting immunomodulators, particularly when used in combination with anti-TNF agents. No adverse reactions are noted following vaccination.

\section{Meningococcal vaccine}

Meningococcal disease is a rare but serious and lifethreatening illness caused by the bacterium Neisseria meningitides. Meningococcal infection can cause sepsis and meningitis resulting in permanent disabilities and rarely death. Individuals living in college dormitories, traveling to endemic areas, military recruits, laboratory personnel, and healthcare workers who are exposed routinely to Neisseria meningitides, patients with complement deficiencies, and asplenia are at high risk of developing a meningococcal infection.

Available meningococcal vaccines include quadrivalent conjugate vaccines (for protection against serogroups $\mathrm{A}, \mathrm{C}$, $\mathrm{Y}$, and $\mathrm{W}$ ) and monovalent vaccines (for protection against serogroups A, B, and C). In India, presently two conjugate vaccines, the quadrivalent vaccine and the monovalent vaccine against A serotype, are available for use. A vaccine against serotype B is generally recommended in the West. A two-dose primary series of quadrivalent conjugate vaccines administered 8-12 weeks apart is recommended for persons aged 24 months through 55 years [52]. No study to date has assessed the immunogenicity of the meningococcal vaccine in the IBD population. However, as the vaccine is noninfectious, it is safe and recommended for use in at-risk individuals with IBD, regardless of their immunosuppression status.

\section{Typhoid vaccine}

Typhoid is an acute infectious illness associated with fever that is most often caused by the Salmonella typhi bacteria. Typhoid fever continues to have a significant disease burden in India, particularly among young children [53]. The available vaccines for typhoid fever include inactivated whole-cell vaccine, live oral Ty21a vaccine, injectable Vi polysaccharide vaccine, and Vi-rEPA vaccine. The injectable Vi polysaccharide vaccine is currently recommended for use in India. This vaccine is given as a single intramuscular dose of $0.5 \mathrm{~mL}$ after 6 months of age, with revaccination every 3 years [54].

Despite being one of the most frequent causes of bacterial gastroenteritis among the general population, data about the role of Salmonella infection in IBD patients are very scarce and controversial. Some data are suggesting that Salmonella can complicate the IBD course, whereas other studies show that exposure did not worsen outcomes in IBD patients [55-57]. At present, the role of typhoid vaccination in patients with IBD is not clear.

\section{Live vaccines}

\section{Varicella vaccine}

Varicella-zoster virus (VZV) is the generally known for causing highly contagious chickenpox in children and herpes zoster/shingles in adults. The extent and severity of varicella infection in adults in tropical countries like India are significantly greater than the temperate countries [58]. In India, more than $30 \%$ of the population aged more than 15 years is susceptible to varicella infection [59]. A large student body with low immunization rates living in the dormitories provides a fertile ground for transmission of varicella. It highlights the potential role of vaccination in young adults in India [60].

The currently available varicella vaccine is a liveattenuated vaccine of the Oka strain of VZV. This vaccine is indicated in adults without a history of varicella infection. A history of varicella infection should be assessed in all patients with IBD. If the patient denies a history of infection or if the history is uncertain, a titer of VZV should be tested. Patients whose titers are not seroprotective should be vaccinated. Two varicella vaccine doses 4 weeks apart are recommended. The patient should complete the vaccination 4 to 6 weeks before initiating the immunosuppressive therapy. For patients already on immunosuppressant therapy, a 3-month window after stopping this therapy is necessary before administering the vaccine. VZV vaccine is safe and immunogenic when given as per the recommended dosing schedule [61].

\section{Herpes zoster}

Herpes zoster, also referred to as shingles, is a painful dermatomal cutaneous eruption due to the reactivation of latent VZV that occurs more frequently among adults over the age of 60 years. Herpes zoster is common in the Indian population [62]. Patients with IBD worldwide and in India treated with immunosuppressive therapies are at increased risk of developing herpes zoster at an early age compared with the general population [63]. It is also associated with serious morbidity and mortality much more than any other vaccine-preventable disease [64-67].

Both vaccines (varicella and herpes) contain the same liveattenuated virus strain. However, the zoster vaccine contains significantly higher titer of live-attenuated virus (at least 19,400 plaque-forming units per dose) than the varicella vaccine (at least 1350 plaque-forming units per dose). Patients can be given zoster vaccine regardless of their previous 
primary varicella infection or prior history of herpes zoster. The vaccination is efficacious in significantly decreasing the incidence of herpes zoster and post-herpetic neuralgia. Mild reactions at the injection site were the only significant adverse effect noted in the recipients of this vaccine [68]. Zoster vaccine is generally contraindicated in patients on high-dose immunosuppressive therapies. However, given the high risk of developing zoster infection in IBD patients, this vaccine is now indicated even in patients more than 50 years of age with low-dose immunosuppression [69]. In tofacitinib-treated patients with UC, an elevated risk of herpes zoster (HZ) is noted [70]. Tofacitinib-containing Xeljanz® label (summary of product characteristics) recommends not to use live vaccines among patients under treatment with tofacitinib.

Recently a new recombinant zoster (Shingrix) vaccine is also studied. The vaccine is given as a two-dose series at 0 months and 2 to 6 months after the first dose. It has been shown to significantly reduce the risk of $\mathrm{HZ}$ by $>90 \%$. The recent recommendations suggest that Shingrix is the preferred vaccine for use in immunocompetent adults aged $\geq 50$ years. Shingrix should be safe to administer in the IBD population as it does not contain live HZV. Limited data in immunosuppressed patients (stem cell transplant recipients and human immunodeficiency virus [HIV] patients) suggest that Shingrix was immunogenic in these patient groups. In its preliminary report, it was found to be efficacious and did not exacerbate IBD [71]. Additionally, patients who previously received the live vaccine Zostavax should receive the Shingrix series as recommended. However, it is not yet available in India and also not recommended for patients on immunosuppressants.

\section{Mumps, measles, and rubella vaccines}

The measles-mumps-rubella (MMR) vaccine is usually recommended for all children and unvaccinated adult population. A significant number of adult IBD patients lack immunity to measles [72]. The MMR vaccine is only available in live-attenuated form. This vaccine is contraindicated in patients with IBD treated with immunosuppressive therapy. In patients without a documented history of receiving the MMR vaccine series, MMR titers should be checked during the initial IBD visit. If titers to any of the three viruses are low or absent, patients should be vaccinated with the standard two doses of MMR. Vaccination is safe in the IBD patient as long as the patient has not been on immunosuppressive therapy within the previous 3 months and has no plans to start therapy in the next 1 to 3 months.

\section{Vaccination in special situations}

Immunization in children with IBD should follow the same rules as adults. Patients on high-dose immunosuppression should not receive live vaccines. It is generally not advisable to administer vaccines during flares of IBD as there are concerns regarding the impaired immune response. However, clinicians should ensure that the catch-up immunization of the child is completed at a later date. Vaccines can be administered in patients with IBD and pregnancy if clinically indicated. In general, live vaccines are contraindicated in pregnant women. Influenza and HBV vaccines are recommended in those who are susceptible to this infection. Tdap vaccine can be given in the third trimester of pregnancy [15].

Household contacts of IBD patients with high-dose immunosuppression can receive all inactivated vaccines. Household contact can also receive MMR, varicella, and zoster vaccines. However, if the household contacts develop a rash following vaccination with varicella or zoster, then contact with them should be avoided [13]. Multiple vaccines can be administered during a single office visit. However, care must be taken that each vaccine is injected at a different anatomical site [73].

\section{Immunization: an Indian perspective}

The World Health Organization (WHO), as well as the Government of India, considers childhood vaccination as the priority. However, the focus on adult immunization in India is not yet optimum [74]. Even in a developed country like the USA, the rates of adult vaccination for various vaccinepreventable diseases vary from $23.5 \%$ to $64.5 \%$ [75]. There are many issues like assessing the efficacy, safety, and cost of introducing vaccines for adults at the national level, which are not yet resolved. There is also an urgent need to raise awareness among the health policy makers as well as health care providers regarding this issue. Also, it is challenging to assess seroprotection offered by a particular vaccine, in the absence of titer measurements. However, given the epidemiology and severity of disease, vaccines against HBV, influenza, pneumococcus pneumonia, and herpes zoster should be given some priority over the rest.

Vaccination in adult patients with IBD specifically should become a part of routine practice as it can save a large number of lives in India alone. The quest for newer and better vaccines continues, with evolution in science and technology. The most awaited vaccine in the present scenario would be against the novel corona virus disease-19 (COVID-19).

In conclusion, treating IBD patients often includes taking difficult medical decisions. Gastroenterologists remain primary care providers for them. These patients are immunosuppressed and susceptible to many vaccine-preventable diseases. Hence, vaccinating them is of paramount importance. All the gastroenterologists must have precise knowledge of vaccination in this select group of patients. Vaccination of a patient should be done, taking into account his/her age, comorbidities, IBD disease activity, immunosuppressive therapy, 
nutritional status, the risk of exposure to pathogens, and geographic clustering. Whenever feasible, vaccination should best be initiated before immunosuppression. Furthermore, vaccination should never delay essential medical therapy required in these patients.

\section{Compliance with ethical standards}

Conflict of interest BBS, and MKG declare that they have no conflict of interest.

Disclaimer The authors are solely responsible for the data and the contents of the paper. In no way, the Honorary Editor-in-Chief, Editorial Board Members, or the printer/publishers are responsible for the results/ findings and content of this article.

\section{References}

1. Ng SC, Shi HY, Hamidi N, et al. Worldwide incidence and prevalence of inflammatory bowel disease in the 21st century: a systematic review of population-based studies. Lancet. 2017;390:276978.

2. Kedia S, Ahuja V. Epidemiology of inflammatory bowel disease in India: the great shift east. Inflamm Intest Dis. 2017;2:102-15.

3. Zabana Y, Rodríguez L, Lobatón T, et al. Relevant infections in inflammatory bowel disease, and their relationship with immunosuppressive therapy and their effects on disease mortality. J Crohn's Colitis. 2019;13:828-37.

4. Bitton A, Vutcovici M, Lytvyak E, et al. Selection of quality indicators in IBD: integrating physician and patient perspectives. Inflamm Bowel Dis. 2019;25:403-9.

5. Jess T, Loftus EV Jr, Harmsen WS, et al. Survival and cause specific mortality in patients with inflammatory bowel disease: a long term outcome study in Olmsted County, Minnesota, 1940-2004. Gut. 2006;55:1248-54.

6. Kirchgesner J, Lemaitre M, Carrat F, Zureik M, Carbonnel F, Dray-Spira R. Risk of serious and opportunistic infections associated with treatment of inflammatory bowel diseases. Gastroenterology. 2018;155:337-46.

7. Singh S, Facciorusso A, Dulai PS, Jairath V, Sandborn WJ. Comparative risk of serious infections with biologic and/or immunosuppressive therapy in patients with inflammatory bowel diseases: a systematic review and meta-analysis. Clin Gastroenterol Hepatol. 2020;1:69-81.

8. Liu XQ, Qin L. Treatment strategy of inflammatory bowel disease associated with viral hepatitis. Chin J Gastroenterol Hepatol. 2016;25:1091-3.

9. Irving PM, Gibson PR. Infections and IBD. Nat Clin Pract Gastroenterol Hepatol. 2008;5:18-27.

10. Melmed GY, Ippoliti AF, Papadakis KA, et al. Patients with inflammatory bowel disease are at risk for vaccine-preventable illnesses. Am J Gastroenterol. 2006;101:1834-40.

11. Selby L, Kane S, Wilson J, et al. Receipt of preventive health services by IBD patients is significantly lower than by primary care patients. Inflamm Bowel Dis. 2008;14:253-8.

12. Malhi G, Rumman A, Thanabalan R, et al. Vaccination in inflammatory bowel disease patients: attitudes, knowledge, and uptake. J Crohns Colitis. 2015;9:439-44.

13. Farraye FA, Melmed GY, Lichtenstein GR, Kane SV. ACG clinical guideline: preventive care in inflammatory bowel disease. Am J Gastroenterol. 2017;112:241-58.
14. Wasan SK, Calderwood AH, Long MD, Kappelman MD, Sandler RS, Farraye FA. Immunization rates and vaccine beliefs among patients with inflammatory bowel disease: an opportunity for improvement. Inflamm Bowel Dis. 2014;20:246-50.

15. Rubin LG, Levin MJ, Ljungman P, Ljungman P, et al. 2013 IDSA clinical practice guideline for vaccination of the immunocompromised host. Clin Infect Dis. 2014;58:309-18.

16. Sands BE, Cuffari C, Katz J, et al. Guidelines for immunizations in patients with inflammatory bowel disease. Inflamm Bowel Dis. 2004;10:677-92.

17. Rahier JF, Magro F, Abreu C, et al. Second European evidencebased consensus on the prevention, diagnosis and management of opportunistic infections in inflammatory bowel disease. J Crohns Colitis. 2014;8:443-68.

18. Kim DK, Bridges CB, Harriman KH, Advisory Committee on Immunization Practices (ACIP), ACIP Adult Immunization Work Group. Advisory Committee on Immunization Practices recommended immunization schedule for adults aged 19 years or older-United States, 2016. Am J Transplant. 2016;16:1930-2.

19. Gurav YK, Chadha MS, Tandale BV, et al. Influenza A (H1N1) pdm09 outbreak detected in inter-seasonal months during the surveillance of influenza-like illness in Pune, India, 2012-2015. Epidemiol Infect. 2017;145:1898-909.

20. Tinsley A, Navabi S, Williams ED, et al. Increased risk of influenza and influenza-related complications among 140,480 patients with inflammatory bowel disease. Inflamm Bowel Dis. 2019;25:369-76.

21. de Bruyn JC, Hilsden R, Fonseca K, et al. Immunogenicity and safety of influenza vaccination in children with inflammatory bowel disease. Inflamm Bowel Dis. 2012;18:25-33.

22. Beck CR, McKenzie BC, Hashim AB, et al. Influenza vaccination for immunocompromised patients: systematic review and metaanalysis by etiology. J Infect Dis. 2012;206:1250-9.

23. Harrington JE, Hamilton RE, Wasan SK, et al. Immunogenicity of the influenza vaccine in IBD patients treated with vedolizumab: 730. Am J Gastroenterol. 2018;113:S407-8.

24. Caldera F, Hillman L, Saha S, et al. Immunogenicity of high dose influenza vaccine for patients with inflammatory bowel disease on anti-TNF monotherapy: a randomized clinical trial. Inflamm Bowel Dis. 2020;26:593-602.

25. Rahier JF, Papay P, Salleron J, et al. H1N1 vaccines in a large observational cohort of patients with inflammatory bowel disease treated with immunomodulators and biological therapy. Gut. 2011;60:456-62.

26. Wahl B, O'Brien KL, Greenbaum A. Burden of Streptococcus pneumoniae and Haemophilus influenza type $b$ disease in children in the era of conjugate vaccines: global, regional, and national estimates for 2000-15. Lancet Glob Health. 2018;6:e744-57.

27. Long MD, Martin C, Sandler RS, Kappelman MD. Increased risk of pneumonia among patients with inflammatory bowel disease. Am J Gastroenterol. 2013;108:240-8.

28. Gregory MH, Ciorba MA, Wiitala WL, et al. The association of medications and vaccination with risk of pneumonia in inflammatory bowel disease. Inflamm Bowel Dis. 2020;26:919-25.

29. Ananthakrishnan AN, McGinley EL. Infection-related hospitalizations are associated with increased mortality in patients with inflammatory bowel diseases. J Crohn's Colitis. 2013;7:107-12.

30. Solanki BB, Juergens C, Chopada MB, et al. Le pneumococcal conjugate vaccine in adults 50 to 65 years of age in India: an open-label trial. Hum Vaccin Immunother. 2017;13:2065-71.

31. van Aalst M, Langedijk AC, Spijker R, de Bree GJ, Grobusch MP, Goorhuis A. The effect of immunosuppressive agents on immunogenicity of pneumococcal vaccination: a systematic review and meta-analysis. Vaccine. 2018;36:5832-45.

32. van Aalst M, Garcia Garrido HM, van der Leun J, et al. Immunogenicity of the currently recommended pneumococcal 
vaccination schedule in patients with inflammatory bowel disease. Clin Infect Dis. 2020;70:595-604.

33. Kumar T, Shrivastava A, Kumar A, et al. Viral hepatitis surveillance-India, 2011-2013. MMWR Morb Mortal Wkly Rep. 2015;64:758-62.

34. Park SH, Yang SK, Park SK, et al. Efficacy of hepatitis A vaccination and factors impacting on seroconversion in patients with inflammatory bowel disease. Inflamm Bowel Dis. 2014;20:69-74.

35. Huang ML, Xu XT, Shen J, Qiao YQ, Dai ZH, Ran ZH. Prevalence and factors related to hepatitis $\mathrm{B}$ and $\mathrm{C}$ infection in inflammatory bowel disease patients in China: a retrospective study. J Crohn's Colitis. 2014;8:282-7.

36. Mak JW, Yip TC, Lam HM, et al. P150 Risk of hepatitis flare in patients with previous hepatitis B virus exposure amongst inflammatory bowel disease patients: results from a territory-wide Hong Kong IBD Registry study. J Crohn's Colitis. 2020;14:S212-3.

37. Shale MJ, Seow CH, Coffin CS, Kaplan GG, Panaccione R, Ghosh $\mathrm{S}$. Review article: chronic viral infection in the anti-tumor necrosis factor therapy era in inflammatory bowel disease. Aliment Pharmacol Ther. 2010;31:20-34.

38. Jiang HY, Wang SY, Deng M, et al. Immune response to hepatitis $B$ vaccination among people with inflammatory bowel diseases: a systematic review and meta-analysis. Vaccine. 2017;35:2633-41.

39. Pratt PK, Nunes D, Long MT, Farraye FA. Improved antibody response to three additional hepatitis $\mathrm{B}$ vaccine doses following primary vaccination failure in patients with inflammatory bowel disease. Dig Dis Sci. 2019;64:2031-8.

40. Arora A, Anand AC, Kumar A, et al. INASL guidelines on management of hepatitis B virus infection in patients receiving chemotherapy, biologicals, immunosupressants, or corticosteroids. J Clin Exp Hepatol. 2018;8:403-31.

41. Schillie S, Harris A, Link-Gelles R, Romero J, Ward J, Nelson N. Recommendations of the Advisory Committee on Immunization Practices for use of a hepatitis B vaccine with a novel adjuvant. MMWR Morb Mortal Wkly Rep. 2018;67:455-8.

42. Cohen PA, Jhingran A, Oaknin A, Denny L. Cervical cancer. Lancet. 2019;393:169-82.

43. Arbyn M, Weiderpass E, Bruni L, et al. Estimates of incidence and mortality of cervical cancer in 2018: a worldwide analysis. Lancet Glob Health. 2020;8:e191-e203.

44. Chatterjee S, Chattopadhyay A, Samanta L. HPV and cervical cancer epidemiology-current status of HPV vaccination in India. Asian Pac J Cancer Prev. 2016;17:3663-73.

45. Segal JP, Askari A, Clark SK, Hart AL, Faiz OD. The incidence and prevalence of human papilloma virus-associated cancers in IBD. Inflamm Bowel Dis. 2020 Feb 21.

46. Allegretti JR, Barnes EL, Cameron A. Are patients with inflammatory bowel disease on chronic immunosuppressive therapy at increased risk of cervical high-grade dysplasia/cancer? A meta-analysis. Inflamm Bowel Dis. 2015;21:1089-97.

47. Meites E, Szilagyi PG, Chesson HW, Unger ER, Romero JR, Markowitz LE. Human papillomavirus vaccination for adults: updated recommendations of the Advisory Committee on Immunization Practices. MMWR Morb Mortal Wkly Rep. 2019;68:698-702.

48. MacIntyre CR, Shaw P, Mackie FE, et al. Immunogenicity and persistence of immunity of a quadrivalent Human Papillomavirus (HPV) vaccine in immunocompromised children. Vaccine. 2016;34:4343-50.

49. Dezfoli S, Horton HA, Thepyasuwan N, et al. Combined immunosuppression impairs immunogenicity to tetanus and pertussis vaccination among patients with inflammatory bowel disease. Inflamm Bowel Dis. 2015;21:1754-60.

50. Caldera F, Saha S, Wald A, et al. Lower sustained diphtheria and pertussis antibody concentrations in inflammatory bowel disease patients. Dig Dis Sci. 2018;63:1532-40.
51. Caldera F, McCrone S, Garmoe CA, et al. Lower sustained pertussis concentrations in patients with inflammatory bowel disease on biologic therapy. Gastroenterology. 2017;152:S59.

52. Indian Academy of Pediatrics, Advisory Committee on Vaccines and Immunization Practices (acvip); Vashishtha VM, Kalra A, et al. Indian Academy of Pediatrics (IAP) recommended immunization schedule for children aged 0 through 18 years - India, 2013 and updates on immunization. Indian Pediatr. 2013;50:1095-108.

53. John J, Van Aart CJ, Grassly NC. The burden of typhoid and paratyphoid in India: systematic review and meta-analysis. PLoS Negl Trop Dis. 2016;10:e0004616.

54. Balasubramanian GS, Shah A, Pemde HK, et al. Indian Academy of Pediatrics (IAP) Advisory Committee on Vaccines and Immunization Practices (ACVIP) Recommended Immunization Schedule (2018-19) and update on immunization for children aged 0 through 18 years. Indian Pediatr. 2018;55:1066-74.

55. Szilagyi HA, Gerson M, Mendelson J, Yusuf NA. Salmonella infections complicating inflammatory bowel disease. J Clin Gastroenterol. 1985;7:251-5.

56. Alvarez-Lobos M, Pizarro DP, Palavecino CE, et al. Role of Salmonella enterica exposure in Chilean Crohn's disease patients. World J Gastroenterol. 2013;19:5855-62.

57. Axelrad JE, Joelson A, Green PH, et al. Enteric infections are common in patients with flares of inflammatory bowel disease. Am J Gastroenerol. 2018;113:1530-9.

58. Wolfe S, Centers for Disease Control and Prevention. Epidemiology and prevention of vaccine-preventable diseases. Hamborsky J, Kroger A, editors. Atlanta: US Department of Health \& Human Services, Centers for Disease Control and Prevention; 2015.

59. Arunkumar G, Vandana KE, Sathiakumar N. Prevalence of measles, mumps, rubella, and varicella susceptibility among health science students in a University in India. Am J Ind Med. 2013;56:58-64.

60. Meyers J, Logaraj M, Ramraj B, Narasimhan P, MacIntyre CR. Epidemic varicella zoster virus among university students, India. Emerg Infect Dis. 2018;24:366-9.

61. Hao B, Chen Z, Zeng G, et al. Efficacy, safety and immunogenicity of live attenuated varicella vaccine in healthy children in China: double-blind, randomized, placebo-controlled clinical trial. Clin Microbiol Infect. 2019;25:1026-31.

62. Lee BW. Review of varicella zoster seroepidemiology in India and Southeast Asia. Tropical Med Int Health. 1998;3:886-90.

63. Khan N, Patel D, Trivedi C, et al. Overall and comparative risk of herpes zoster with pharmacotherapy for inflammatory bowel diseases: a nationwide cohort study. Clin Gastroenterol Hepatol. 2018;16:1919-27.

64. Nugent Z, Singh H, Targownik LE, Bernstein CN. Herpes zoster infection and herpes zoster vaccination in a population-based sample of persons with IBD: is there still an unmet need? Inflamm Bowel Dis. 2019:25532-40.

65. Chang K, Lee HS, Kim YJ, et al. Increased risk of herpes zoster infection in patients with inflammatory bowel diseases in Korea. Clin Gastroenterol Hepatol. 2018;16:1928-36.

66. Ning L, Liu R, Li S, et al. Increased risk of herpes zoster infection in patients with inflammatory bowel disease: a meta-analysis of cohort studies. Eur J Clin Microbiol Infect Dis. 2019;18:1-9.

67. Latheef ENA, Pavithran K. Herpes zoster: a clinical study in 205 patients. Indian J Dermatol. 2011;56:529-32.

68. Khan N, Trivedi C, Kavani H, Medvedeva E, Lewis J, Yang Y-X. Efficacy of live attenuated herpes zoster vaccine in patients with inflammatory bowel diseases. Clin Gastroenterol Hepatol. 2019;17: 1341-7.

69. Wasan SK, Zullow S, Berg A, Cheifetz AS, Ganley-Leal L, Farraye FA. Herpes zoster vaccine response in inflammatory bowel disease patients on low-dose immunosuppression. Inflamm Bowel Dis. 2016;22:1391-6. 
70. Winthrop KL, Melmed GY, Vermeire S, et al. Herpes zoster infection in patients with ulcerative colitis receiving tofacitinib. Inflamm Bowel Dis. 2018;24:2258-65.

71. Reich J, Pei-Hsuan L, Zahorian T, et al. Use of recombinant zoster vaccine (RZV-Shingrix) in patients with inflammatory bowel disease: 712. Am J Gastroenterol. 2018;113:S400.

72. Cleveland NK, Rodriquez D, Wichman A, Pan I, Melmed GY, Rubin DT. Many inflammatory bowel disease patients are not immune to measles or pertussis. Dig Dis Sci. 2016;61:2972-6.

73. Fiore AE, Uyeki TM, Broder K, et al. Prevention and control of influenza with vaccines: recommendations of the Advisory
Committee on Immunization Practices (ACIP), 2010. MMWR Recomm Rep. 2010;59:1-62.

74. Verma R, Khanna P, Chawla S. Adult immunization in India: Importance and recommendations. Hum Vaccin Immunother. 2015;11:2180-2.

75. Centers for Disease Control and Prevention. Vaccination coverage among adults in the United States, National Health Interview Survey, 2017.

Publisher's note Springer Nature remains neutral with regard to jurisdictional claims in published maps and institutional affiliations. 